\title{
Diglosia y Bilingüismo entre los Chanés: una Reflexión Crítica
}

\author{
María Agustina Morando ${ }^{1,2,3}$ \\ ${ }^{1}$ Consejo Nacional de Investigaciones Científicas y Técnicas, Ciudad Autónoma de Buenos Aires, \\ Buenos Aires, Argentina. \\ ${ }^{2}$ Pontificia Universidad Católica Argentina, Instituto de Investigaciones, Facultad de Ciencias \\ Sociales, Ciudad Autónoma de Buenos Aires, Buenos Aires, Argentina \\ ${ }^{3}$ Centro de Investigaciones Históricas y Antropológicas, Santa Cruz de la Sierra, Santa Cruz, Bolivia
}

\section{Resumen}

Cerca de 2.100 personas se reconocen como "chanés" en Argentina, concentrándose la mayor parte en la provincia de Salta. A lo largo de su historia, este grupo indígena atravesó por dos procesos profundos de quiebre lingüístico, razón por la cual es hoy en día mayormente bilingüe en guaraní chaqueño y en castellano. Esto determina, a su vez, que el problema de la relación con la lengua cobre particular relevancia para la definición de lo identitario. El propósito de este trabajo es, entonces, estudiar etnográficamente las prácticas comunicativas bilingües por medio de un análisis antropológico de los contextos de acción cotidianos del bilingüismo, de las ideologías individuales y colectivas en torno del uso situacional de la lengua indígena y del castellano, así como de sus efectos en la construcción de la identidad étnica grupal y los procesos de organización social.

Palabras claves: Prácticas comunicativas. Diglosia. Bilingüismo. Indígenas chaqueños. Chanés.

\section{Diglossia e Bilinguismo entre os Chané: uma Reflexão Crítica}

\section{Resumo}

Cerca de 2.100 pessoas se reconhecem como "Chanés" na Argentina, a maioria delas na província de Salta. Ao longo de sua história, esse grupo indígena passou por dois processos profundos de ruptura linguística, razão pela qual é hoje, em sua maioria, bilíngue em guarani chaquenho e espanhol. Isso determina que o problema da relação com a língua se torne relevante para a definição da sua identidade. O objetivo deste trabalho é, portanto, estudar etnograficamente as práticas comunicativas bilíngues por meio de uma análise antropológica dos contextos de ação diária do bilinguismo, das ideologias individuais e coletivas em torno do uso situacional da língua indígena e do espanhol, bem como de seus efeitos na construção da identidade étnica do grupo e dos processos de organização social.

Palavras-chave: Práticas Comunicativas. Diglossia. Bilinguismo. Indígenas Chaquenhos. Chanés. 


\section{Introducción}

$\mathrm{E}$ n la actualidad, aproximadamente 2100 (INDEC, 2004-2005) personas se reconocen como "chanés" en Argentina, concentrándose la mayor parte de ellas en cuatro poblados del departamento San Martín de la provincia de Salta: Tuyunti, Campo Durán, fkira y El Algarrobal. Los chanés constituyen un grupo indígena de origen arawak que, tras un masivo proceso migratorio, se asentó en el oeste del Gran Chaco, sobre el piedemonte andino. De acuerdo con las fuentes coloniales allí, a partir del siglo XVI, padecieron un intenso proceso de "guaranización" en manos de grupos tupí-guaraníes que a su vez llegaban a la región piedemontana, lo cual dio origen a una "civilización mixta" o "sociedad mestiza" conocida por la etnografía regional bajo el nombre de "chiriguana", "chiriguano" o "chiriguanaes" (MÉTRAUX, 1948; MAGRASSI, 1968; SUSNIK, 1968; ROCCA, 1973; COMBÈS; SAIGNES, 1995; SAIGNES, 2007).

De esta forma, a lo largo de su historia los chanés atravesaron por un doble proceso de quiebre lingüístico. En una primera instancia, debido a su mestizaje con estos grupos de origen tupí-guaraní, los chanés comenzaron paulatinamente a adoptar muchos rasgos culturales de origen guaraní produciéndose un desplazamiento ${ }^{1}$ de la antigua lengua arawak (COMBÈS, 2007; BOSSERT, 2008), en un proceso que a grandes rasgos podría reconocerse bajo el nombre de "guaranización". Posteriormente, con el establecimiento de misiones jesuitas y luego franciscanas en el Chaco durante los siglos XVII y XX (LANGER, 1995), los chanés atravesaron por un profundo proceso de "castellanización". Esto determina a su vez que el problema de la relación con la lengua cobre gran relevancia para la definición de lo identitario en el caso de este grupo indígena.

Los chanés hablan hoy en día una lengua reconocida bajo el nombre de "guaraní chaqueño" o "chiriguano", perteneciente a la rama meridional de la familia lingüística tupí-guaraní que posee cuatro dialectos principales -el ava, el chané, el simba y el isoseñoy es hablada por cerca de 70.000 personas en el sureste boliviano, el noroeste argentino y algunos sectores dispersos del Oeste de Paraguay (DIETRICH, 1986; AIKHENVALD, 1999; GUSTAFSON, 2014). A pesar de ello, es preciso no juzgar la integración chané dentro de este conjunto "guaraní-chiriguano" como un proceso de asimilación absoluta, debido principalmente al hecho de que la antigua herencia arawak es perceptible aun en la cultura material - técnicas de alfarería, tejido o confección de máscaras -, en las formas de organización sociopolítica - organización de la autoridad política o del trabajo

Entiendo aquí el concepto de "desplazamiento lingüístico" desde la perspectiva de Thomason (2001) como el reemplazo paulatino de una lengua -que viene a ocupar una posición hegemónica- por otra en un contexto de contacto lingüístico asimétrico, mediante el cual se produce una adaptación de las funciones comunicativas, contextos de uso y repertorios de cada una de las lenguas. 
colectivo - e incluso en algunos marcadores lingüísticos relevantes para comprender la construcción de las relaciones intra e interétnicas (COMBÈS; VILLAR, 2004; VILLAR, 2006; MORANDO, 2015). Esto explica también que, a través de la historia, los chanés hayan mantenido una conciencia clara de su diferencia étnica, más puntualmente en la cuenca del río Itiyuro (NORDENSKIÖLD, 2002 [1912]; PALAVECINO, 1949; COMBÈS, 2005; VILLAR, 2006; BOSSERT; COMBÈS; VILLAR, 2008; VILLAR; BOSSERT, 2014; MORANDO, 2015, 2021; DOMÍNGUEZ, 2018).

Los chanés representan una población predominantemente rural; de hecho, cuantitativamente hablando, según los números provistos por la Encuesta Complementaria de Pueblos Indígenas (INDEC, 2004-2005), podemos decir que 92\% de esta población vive en poblados indígenas rurales y reconocidos como tales, mientras que solamente un $8 \%$ lo hace en poblados no-indígenas. Los cuatro poblados chanés cuentan con escuela primaria, en la cual los números actuales muestran que, de la población chané de diez años o más, el grado de alfabetismo alcanza un $92 \%$ y el analfabetismo un $8 \%$. Si atendemos a la variante de edad y género, lo que podemos decir es que el nivel de alfabetización es mayor entre los niños y jóvenes y menor entre los adultos. El alfabetismo alcanza también niveles más altos entre los hombres (94\%) que entre las mujeres (90\%). Ninguno de los poblados chanés cuenta actualmente con establecimientos escolares de nivel secundario o superior, por lo que aquellos niños y jóvenes que continúan sus estudios deben hacerlo necesariamente en otros lugares cercanos como Aguaray, Tartagal o Salvador Mazza.

En lo que se refiere específicamente a la lengua indígena, los datos estadísticos indican que, de la población de cinco años o más que se reconoce como "chané" en la provincia de Salta, 63\% dice hablar y entender la lengua indígena, 18\% sostiene que no la habla, pero sí la entiende, y finalmente otro $18 \%$ afirma que no la habla ni la entiende. Si atendemos a la variable "sexo", podemos decir que, del total de la población masculina, el 63\% habla y entiende la lengua indígena, 17\% no la habla, pero sí la entiende y $20 \%$ no la habla ni la entiende. En lo que se refiere a la población femenina, 63\% habla y entiende la lengua, $20 \%$ no la habla, pero sí la entiende y el $17 \%$ restante no la habla ni la entiende.

Si tomamos los datos oficiales acerca del uso de lenguas en el ámbito doméstico, podemos apreciar que, en el rango entre 5 y 14 años, existe un 14\% de personas que solamente utiliza la lengua indígena, un 15\% que se maneja tanto en la lengua indígena como en castellano y un $71 \%$ que lo hace mayoritariamente en castellano. En la franja de 15 y 29 años, 17\% utiliza la lengua indígena en la cotidianeidad, 31\% usa ambas lenguas y 52\% únicamente el castellano. Entre las personas de 30 a 39 años, 25\% utiliza exclusivamente la lengua indígena en la vida cotidiana, 36\% ambas lenguas y el restante $38 \%$ el castellano. Entre aquellos que se encuentran en el grupo etario comprendido entre los 40 y los 59 años, un 33\% utiliza la lengua indígena, 42\% la lengua indígena y el castellano, y 25\% el castellano. Entre aquellos que tienen más de 60 años, se observa por fin que 57\% utiliza en la cotidianeidad la lengua indígena, 30\% la lengua indígena y el castellano y $12 \%$ únicamente el castellano. Ésta es, entonces, a grandes rasgos la situación sociolingüística chané considerada desde un punto de vista externo y estadístico.

Debido a la coyuntura etnohistórica a la que hice mención anteriormente, y tal como parecen confirmar en primera instancia los datos estadísticos, los chanés son, hoy en 
día, mayormente bilingües, por lo que puede observarse en la cotidianeidad actual una coexistencia de prácticas y usos comunicativos en guaraní chaqueño (ñande ñee 'nuestra lengua') y en castellano (karai ñee 'la lengua de los criollos'). Ahora bien, debido a las características propias del mecanismo por medio del cual se obtienen los datos estadísticos (encuestas con preguntas cerradas realizadas en un lapso de tiempo muy breve), estos poseen algunas limitaciones que no permiten profundizar demasiado en la situación sociolingüística del caso en cuestión. Estos datos precisan ser complementados con otros datos cualitativos, obtenidos en el terreno con los propios colaboradores nativos, que nos permiten realizar un acercamiento mucho más completo al uso efectivo de las prácticas comunicativas. Sobre ello, justamente, profundizaré en este trabajo.

Teniendo en cuenta esto, el propósito será estudiar etnográficamente las prácticas comunicativas bilingües chanés por medio de un análisis antropológico de los contextos de acción cotidianos del bilingüismo, de las ideologías individuales y colectivas en torno del uso de la lengua indígena y del castellano - el “[...] conjunto de creencias sobre la lengua articulados por sus hablantes como racionalización o justificación de la estructura y el uso de la lengua percibidos [...]" (SILVERSTEIN, 1979, p. 193) -, así como también de sus efectos en la construcción de la identidad étnica grupal y los procesos de organización social.

Parto, entonces, de la hipótesis de que los chanés integrarían una "comunidad de habla" compleja -entendida como un grupo social que comparte una serie determinada de reglas comunicativas y performativas (GUMPERZ; HYMES, 1972, p. 16-17) -, y que esta comunidad es fundamentalmente bilingüe. Sin embargo, en ella existen hablantes que poseen una "competencia comunicativa" - o facultad de modelar enunciados que no sólo sean gramaticalmente correctos sino también socialmente apropiados (HYMES, 1971, p. 16) -; y que dicha competencia resulta en muchos casos mucho más sólida en castellano que en la lengua indígena; en otros, por el contrario, resulta más sólida en la lengua indígena y, entre ambos polos, encontramos asimismo una amplia gama de matices y situaciones diferentes - la pregunta, por tanto, es si ello encuentra eco en alguna correlación sociológica. Además, parto de la base de considerar que se trata de una situación de bilingüismo con diglosia; es decir, de una situación de contacto asimétrico de lenguas - o variedades e incluso sociolectos de una misma lengua- en una comunidad de habla, en la que cada una posee una funcionalidad particular y ello está asociado con determinados contextos sociales (FERGUSON, 1959; FISHMAN, 1965).

Este trabajo está basado en una investigación en curso desde el año 2012, para la cual realicé doce campañas de campo a los poblados chanés del noroeste argentino totalizando diecinueve meses de permanencia en el terreno. A mi llegada al campo visité inicialmente los poblados chanés demográficamente más grandes (Tuyunti y Campo Durán), para luego, en las sucesivas campañas, volver a esos mismos lugares y

\footnotetext{
La propuesta teórica de Hymes sobre el concepto de "competencia comunicativa" se presenta como una reacción contra el enfoque de Chomsky (1965, p. 4), de inclinación más bien formalista e interesado por la lengua cifrada en lo que llamaba "competencia lingüística"; es decir, el conocimiento implícito que un hablante posee de su lengua, consistente en una serie de procesos generativos que le permiten comprender y producir enunciados. Por el contrario, el abordaje teórico propuesto por Hymes enfoca explícitamente el estudio del uso social de la lengua, lo cual implica una remisión directa al contexto como elemento base para la organización de sus registros y el conocimiento y manejo de una serie de reglas de actuación lingüística a nivel pragmático y metapragmático.
} 
visitar asimismo los poblados chanés más pequeños (łkira y El Algarrobal), así como también otros asentamientos de la zona en los que existe alguna población minoritaria de ese origen étnico como Capiazuti, Peña Morada o Campo Blanco. Trabajé en total con dieciséis grupos familiares, en cuyo seno encontré hablantes que poseían distintos tipos de competencia comunicativa. El contacto con distintos grupos familiares me permitió, entre otras cosas, la posibilidad de observar cotidianamente las diferencias que existen entre el uso de la lengua indígena y el castellano, como así también los primeros matices de edad, género o generación. Me valí principalmente de técnica cualitativa de la "observación participante"; sin embargo, para recoger datos preferí no utilizar un enfoque tradicional con entrevistas de tipo "abiertas", "semi-estructuradas", "cerradas", etc. Más bien, en consonancia con la propuesta de Briggs (1986), opté por atenerme al formato de conversación cotidiana, a fin de evitar imponer un género cuyas normas comunicativas no son utilizadas en la cotidianeidad de muchas comunidades de habla.

Para llevar a cabo mi análisis abordaré en los subsiguientes apartados algunos dominios sociales que pueden resultar diagnósticos en el estudio de la situación de contacto lingüístico - véase, por ejemplo, Dreidemie (2006); Hecht (2006, 2010); Admiraal (2006) y Ciccone (2015): familia y comunidad, escuela, religión y medios de comunicación. Estos contextos, sin dudas, podrán ofrecer una pauta de algunos de los modos contemporáneos en los que los hablantes de esta lengua despliegan y negocian los usos del castellano y del guaraní chaqueño.

\section{Familias “Tradicionales" y Familias "Entreveradas"}

Si apuntamos a entender qué es lo que hace que algunos chanés hablen más la lengua indígena o el castellano que otros, el panorama inicial que nos brinda la estadística de bilingüismo chané debe complementarse - y sobre todo contextualizarse - desde un punto de vista etnográfico. En primer lugar, podemos abordar el problema del bilingüismo chané diciendo que en la cotidianeidad advertimos al menos dos grandes relaciones diferenciales con la lengua, construidas prioritariamente en función de diversas afiliaciones sociales. A nivel familiar, por un lado, encontramos ciertas facciones o parcialidades que parecen perder o alterar la lengua indígena y definir su identidad colectiva independientemente del factor lingüístico y, por otra parte, otras que definen consistente y explícitamente su identidad étnica - entre otras tantas variables - en torno, precisamente, de la cuestión de su uso y conservación.

Esto nos lleva inevitablemente a la división que observan los propios hablantes entre aquellas familias chanés que se identifican como familias "tradicionales" y otras que, por tanto, podríamos caracterizar como "entreveradas", "advenedizas" o "no tradicionales". Es importante remarcar que esta identificación como familia "tradicional" o "no tradicional" parece establecerse a través de la identificación o del contraste con los llamados tenondea o "antiguos"; es decir, con los "antepasados". El hecho de que los tenondea tuvieran un menor contacto con los karai (o "criollos") los presenta como poseedores de atributos positivos, uno de los cuales, precisamente, sería la conservación de la lengua indígena. Según los miembros de las familias "tradicionales", debido al creciente contacto con la 
sociedad criolla el ñee "puro" estaría paulatinamente desapareciendo. A pesar de ello, afirman que la lengua se mantiene en ellas: no sólo porque utilizan efectivamente la lengua en su vida cotidiana sino porque, al mismo tiempo, insisten reflexivamente en la necesidad de conservarla y sólo recurren al castellano en caso de ser estrictamente necesario: por ejemplo, en el ámbito escolar, o bien en el ámbito de las relaciones cotidianas con los criollos.

Entre estas familias "tradicionales", se encuentra naturalmente la familia de los mburuvichareta o "caciques". La familia cacical desempeña un papel fundamental en el mantenimiento de la identidad chané y suele presentarse como protectora y conocedora de la cultura, así como de la lengua. Estas familias consideradas como "herederas de los antiguos" y defensoras de un ñee más "puro" - utopía lingüística claramente ligada con las ideologías sobre los usos de la lengua - consideran muchas veces a la lengua indígena como modo de mantener la confidencialidad en la interacción social (ZIMMERMAN, 2006). Si bien estas familias reconocen que hablar castellano se revela particularmente conveniente en ciertas situaciones cotidianas, la lengua indígena ocupa todavía un lugar ciertamente relevante en la configuración de su identidad como chanés (COMBÈS; VILLAR, 2004).

Las personas que se identifican como miembros de las familias "entreveradas", "advenedizas" o "no tradicionales", por el contrario, han dejado mayormente de transmitir la lengua indígena, argumentando por lo general que su enseñanza tendría un efecto negativo sobre el aprendizaje general de los niños; por ejemplo, en el caso de que éstos pretendan continuar sus estudios secundarios u obtener un puesto de trabajo fuera del poblado. Por tales razones, la mayoría de los miembros de estas familias eligen conscientemente transmitir el castellano en detrimento del guaraní chaqueño. Éstas son concebidas en la región, por tanto, como familias que estarían atravesando por un proceso de "acriollamiento" debido a su reticencia a transmitir la lengua indígena.

El uso del guaraní chaqueño predomina, entonces, en el seno de las familias más vinculadas con la tradición cacical, así como el castellano prima en la rutina comunicacional cotidiana de aquellas otras familias que se consideran "cruzadas" o "entreveradas" debido a su mayor contacto con criollos, guaraníes, tapietes u otros indígenas chaqueños. Esto explica que en el campo podamos encontrar hablantes que poseen distintos niveles de competencia en diversos géneros orales.

El problema se profundiza aún más en los casos de los matrimonios interétnicos chané-criollo, ya que esto está relacionado con la situación sociolingüística de la familia de la cual provienen los progenitores. En líneas generales, en los casos en los que uno de ellos proviene de una familia indígena "tradicional", la socialización de los niños se produce en la mayor parte de los casos en guaraní chaqueño y en castellano, mientras que en aquellos casos en los que uno de los progenitores proviene de una familia indígena "no-tradicional" esta se produce mayormente en castellano.

Los matices de la práctica bilingüe, los grados de competencia comunicativa que cada hablante posee en la lengua indígena y en castellano y, sobre todo, la posición ocupada por cada hablante en la estructura social, son entonces determinantes de gran importancia en la ejecución de tales o cuales géneros discursivos. Esto resulta todavía más claro en determinados géneros orales que podemos observar ejecutados mayormente 
en la lengua indígena tales como arakae ndaye "relatos del pasado mítico", karamboe ndaye "relatos del pasado histórico", pirae "cantos" o mbirae "fórmulas curativas". En el caso de los mbirae o "fórmulas curativas", por ejemplo, lo que sucede es que suelen ser utilizadas exclusivamente por hablantes que no sólo poseen una competencia sólida en la lengua indígena, sino que también conocen los contextos pragmáticos de utilización porque han sido formados en ello por algún familiar. Además de ello, ponen estos conocimientos constantemente en práctica y ocupan, por esta razón, una posición de importancia en la estructura social. De hecho, los especialistas en la aplicación de estas fórmulas o ipayes, generalmente, son reconocidos a nivel local y suelen recibir frecuentemente visitantes - tanto indígenas como no indígenas - que buscan sanar alguna dolencia.

Ahora bien, en las últimas décadas ha comenzado asimismo un fenómeno de visibilización identitaria y revitalización de la lengua indígena - que en el noroeste argentino no sólo alcanza a los chanés (CICCONE, 2015) -, y que abre una nueva vía para remediar ese corte en la transmisión intergeneracional de la lengua entre las familias "entreveradas", "advenedizas" o "no tradicionales" y las "tradicionales". En este proceso las escuelas han adquirido un papel notable, puesto que mediante la implementación de programas de Educación Intercultural Bilingüe nacionales y el contacto de muchos docentes chanés con guaraní hablantes de otros poblados de la zona, e incluso de Bolivia, se ha tratado de revalorizar el uso cotidiano de la lengua indígena. Sin embargo, la efectividad concreta de estos programas para revertir el corte generacional en la transmisión de la lengua aún resta por ser estudiada en profundidad en el largo plazo. Podríamos decir, entonces, que estas "actitudes" hacia el uso de una u otra lengua en ciertos contextos estarían influenciadas por valores socioculturales adjudicados por los hablantes a cada una de ellas en función de su estatus social o su posición en la estructura de la comunidad de habla (MORENO FERNÁNDEZ, 2012 [1998], p. 177).

\section{El Ámbito Educativo y el Bilingüismo}

La escuela ocupa un espacio importante en la vida de todos los poblados chanés. A partir de la misma los niños ingresan en un campo de múltiples disputas y tensiones entre las distintas ideologías que circulan al interior y fuera de los poblados acerca de los diferentes usos del guaraní chaqueño y del castellano. Según describen muchos adultos mayores, la escuela fue donde tuvieron su primer contacto con la lengua castellana. De hecho, hasta la década de 1980, el uso de la lengua indígena fue desalentado en el aula, imponiéndose sanciones disciplinarias a aquellos estudiantes que la utilizasen. Esto se fundaba, sobre todo, en la supuesta dificultad de los niños indígenas para aprender el castellano mientras continuaran hablando la lengua indígena, y las sanciones variaban desde una simple llamada de atención verbal hasta la aplicación castigos físicos - por ejemplo, arrodillarse sobre maíz, o bien golpes con una regla. Además de ello, recurrentemente se castigaban los "usos incorrectos" del castellano. En términos generales, las representaciones en torno de la escuela y su relación con la lengua indígena conformaron con los años una visión principalmente negativa. 
Ahora bien, hacia la década de 1980 comenzaron a surgir en Argentina - como también en el resto de Sudamérica - iniciativas y modelos pedagógicos alternativos capaces de adaptarse mejor a las necesidades educativas indígenas. De hecho, los primeros intentos de impulsar modelos pedagógicos interculturales y bilingües suceden en las provincias de Formosa, Salta y Chaco. Este tópico acaba por insertarse de manera definitiva en el ámbito nacional mediante la aprobación de la Ley Federal de Educación n. 4.195, en 1993, una de cuyas particularidades es poner de manifiesto la relevancia de la preservación y promoción de las lenguas indígenas en el ámbito escolar (HIRSCH; SERRUDO, 2010, p. 34). Esta ley es derogada y reemplazada por la Ley de Educación Nacional n. 26.206, en el año 2006, y por medio de ella se establece la Modalidad Intercultural Bilingüe dentro del sistema educativo como una dentro de las ocho modalidades del sistema educativo formal.

En el caso particular de la provincia de Salta, también se impulsaron diversas iniciativas que contribuirían a comprender el desarrollo del proyecto de una Educación Bilingüe e Intercultural. Una de las primeras es la creación del "Proyecto de Regionalización Educativa para el Área Aborigen (PREPARA)" en el año 1984. A partir de este proyecto, se incorpora al sistema educativo el cargo de "Auxiliar Aborigen del Docente". Sin embargo, esto se realizó sin una reglamentación que definiera las condiciones de su trabajo. Entre otros, en el año 2000, se sanciona la Ley n. 7.121 de "Desarrollo de los Pueblos Indígenas de Salta", que impulsa las bases curriculares de los programas de Educación Intercultural Bilingüe. Ya en el año 2010, inclusive, se creó un Profesorado de Educación Intercultural Bilingüe de Educación Primaria con sede en la ciudad de Tartagal, cuyo propósito era conformar un espacio de capacitación de educadores - tanto indígenas como no indígenas - formados para trabajar en contextos indígenas.

En la actualidad, todas las escuelas de los poblados chanés cuentan con nivel inicial y primario y solamente algunos grados cuentan con maestros auxiliares bilingües de origen indígena, que trabajan en conjunto con docentes criollos a través del método de "pareja pedagógica", un sistema que articula el trabajo del docente no indígena y del docente indígena en el aula. Los maestros auxiliares bilingües son responsables de la alfabetización en lengua indígena mientras que los maestros de grado se focalizan en la enseñanza en castellano; en términos ideales, entonces, esta metodología propone una división de tareas según la cual ambos docentes trabajarían de manera simultánea los contenidos pedagógicos. Sin embargo, a pesar de esto, puede observarse que en la práctica muchos auxiliares bilingües realizan tareas no necesariamente pedagógicas como servir el desayuno y el almuerzo, preparar la decoración para los actos escolares, contactar a las familias de los niños y niñas en circunstancias puntuales.

El papel del auxiliar bilingüe incluye también la función de constituir una suerte de "interlocutor cultural" entre la escuela y los habitantes del poblado, desempeñándose como referente social relevante para los niños indígenas, sobre todo en el caso de aquellos que ingresan al sistema escolar con escasos conocimientos del castellano. No sólo ello, sino que, además, el maestro auxiliar bilingüe cobra una gran importancia en su papel de "rescate cultural", lo cual implica casi inevitablemente la promoción de ciertas prácticas de recuperación de la lengua, pero también de cuentos, cantos y saberes tradicionales 
(HECHT, 2006, 2010; CICCONE; HIRSCH, 2010; HIRSCH; SERRUDO, 2010; PETZ, 2010; WALLIS, 2010; BORTON et al., 2010).

Una cuestión interesante sobre este punto es el proceso de selección de los maestros auxiliares bilingües. El proceso de selección es prerrogativa de cada poblado, cuyos habitantes eligen entre los jóvenes que se consideran más idóneos. Entre ellos, naturalmente, se encuentran muchos miembros de las familias "tradicionales" que - por las razones anteriormente expuestas - suelen ser los que cuentan con una competencia comunicativa más sólida en guaraní chaqueño. La decisión debe tomarse necesariamente en una 'asamblea comunitaria' o yemboati, durante la cual cada candidato debe presentar una postulación pública. Una vez que los candidatos son elegidos a través del voto, deben ser avalados por el cacique. Por lo general se escogen para estos cargos a personas que se encuentren ya vinculadas con la enseñanza; por ejemplo, por encontrarse formándose en la carrera docente, o bien por haber realizado alguna capacitación en esa área.

Es importante aclarar, asimismo, que los chanés cuentan con un alfabeto propio desde el año 1989. Este alfabeto ha sido adoptado desde Bolivia, donde en 1987 ya se había aprobado por ley para las lenguas guaraníes. Además de ello, desde fines de la década de 1980 y durante toda la década de 1990, los Consejos Educativos de Pueblos Originarios (CEPOs) de Bolivia comenzaron a impulsar una serie de programas educativos interculturales y bilingües que tuvieron una cierta resonancia entre los poblados chanés del lado argentino. Esta influencia guaraní boliviana comenzó a ser más intensa luego de la creación en 1987 de la Asamblea del Pueblo Guaraní (APG) en Bolivia, organización indígena que hasta el día de hoy actúa como órgano máximo de representación del pueblo guaraní en ese país (HIRSCH, 2003) . $^{3}$.

Líderes de esta organización llegaron entonces a visitar distintos poblados guaraní hablantes del noroeste argentino con el objetivo de organizar cursos y capacitaciones para los docentes indígenas. Inclusive en el poblado de Tuyunti, durante la década de 1990, se llevaron a cabo varios encuentros en los que participaron docentes guaraní hablantes provenientes de Bolivia, quienes también aportaron material para la confección de cartillas y libros. Esta influencia del guaraní boliviano en la escolarización bilingüe de los chanés ha generado puntos de vista encontrados. Si hay algunos chanés que la valoran positivamente, frente al avance de un guaraní proveniente de Bolivia se manifiesta también en otros sectores - sobre todo los conformados por aquellos chanés considerados más "tradicionales" - una evidente resistencia. En esta disputa por el contenido de la lengua indígena en el contexto escolar, existe por tanto un cruce fundamental entre lengua e identidad étnica.

Señalé previamente que entre los chanés existe una gran variación con respecto a la competencia comunicativa en la lengua indígena y en castellano, y que esto puede apreciarse también en el ámbito escolar. En efecto, puede hablarse de un continuo de situaciones en uno de cuyos polos encontramos niños que han crecido en familias en las cuales la socialización se produce preferentemente en castellano, y por lo tanto en las cuales la lengua indígena ha perdido casi totalmente su funcionalidad por no haber

La Asamblea del Pueblo Guaraní está integrada actualmente por 24 capitanías situadas en cinco provincias de tres departamentos de Bolivia: provincia Cordillera (departamento de Santa Cruz de la Sierra), provincias Hernando Siles y Luis Calvo (departamento de Chuquisaca) y provincias Gran Chaco y O'Connor (departamento de Tarija). 
hablantes competentes o bien por no ser transmitida por diversas razones: vergüenza, discriminación, futuras imposibilidades reales o presuntas en lo referido a la educación o a lo laboral. En el polo opuesto encontramos a otros niños que han crecido en familias en las que la lengua indígena posee un alto grado de vitalidad y es hablada frecuentemente por personas de distintas generaciones en diversos ámbitos y registros cotidianos. Por lo tanto, la socialización en esas familias se produce preferentemente en esta lengua, dando como resultado niños que ingresan al sistema escolar con escasos conocimientos del castellano. Entre ambos polos, naturalmente, existe una gama de situaciones intermedias.

A lo largo del nivel inicial y los primeros años de la escuela primaria, aquellos niños que no poseen una competencia comunicativa sólida en castellano se apoyan en los maestros auxiliares bilingües, ya que con ellos pueden expresarse en la lengua indígena. En algunos casos, mientras el maestro de grado lee un cuento o presenta una actividad, el maestro auxiliar bilingüe traduce aquello que ha sido dicho a los niños que no poseen suficiente capacidad comunicativa en castellano. Ellos siguen la clase a partir de la traducción del maestro auxiliar bilingüe, tomándolo como punto de apoyo lingüístico. Por el contrario, aquellos niños que poseen una fuerte competencia comunicativa en castellano seguirán la clase a partir de lo dicho por el maestro de grado criollo y se referirán a él en el caso de que se les presente alguna duda o problema.

En algunos casos, los maestros de grado criollos consideran - al menos discursivamente - que sería necesario para ellos aprender la lengua de los chanés a fin de disponer de una mejor comunicación con los estudiantes. Sin embargo, y a pesar de esto, no realizan mayormente acciones concretas para aprenderla; de hecho, en lo que se refiere a la incorporación de la lengua indígena en la currícula escolar, hasta argumentan en algunos casos - tal como sucedía en el pasado - que la enseñanza de la lengua nativa podría tener efectos contraproducentes en el aprendizaje del castellano.

Siguiendo a Siguán y Mackey (1986) podríamos decir entonces que, en el caso chané, la implementación del modelo de Educación Intercultural Bilingüe adopta en los primeros grados - que cuentan con un maestro auxiliar - una "modalidad bilingüe transitoria" en la que al niño monolingüe en la lengua indígena se lo introduce al castellano y, viceversa, al niño monolingüe en castellano se lo introduce - si bien parcialmente - a la lengua indígena. Además, se observa una consolidación de la condición de bilingües en los casos de los niños que ingresan al sistema escolar con competencia en ambas lenguas. En los grados más avanzados, por el contrario, lo que sucede es que el sistema parece avanzar progresivamente hacia una "monoalfabetización" casi total en castellano, como consecuencia de que no se cuenta ya con la asistencia continua de un maestro auxiliar bilingüe. Esto provoca, por un lado, que los niños que solamente hablaban la lengua indígena al comenzar su escolarización devienen hablantes bilingües por el creciente contacto con el castellano y, por el otro, que los niños que al comienzo de su escolarización eran hablantes monolingües en castellano alcancen ese nivel de escolarización habiendo atravesado solamente una inmersión parcial en la lengua indígena, pudiendo considerárseles como "semi-lingües" (DORIAN, 1977) en ella. Esto implica que en muchos casos poseen una cierta "competencia comunicativa", con lo cual conocen las reglas pragmáticas y metapragmáticas que rigen la comunicación en 
la lengua indígena, pero no dominan por completo muchos aspectos relacionados con la gramática.

\section{La Religiosidad y las Representaciones e Ideologías sobre las Prácticas Bilingües}

Los contextos religiosos también pueden revelar las diversas modalidades contemporáneas de la acción lingüística y sus matices. Por esta razón, trataré brevemente lo que sucede con las prácticas comunicativas que guardan relación con la dinámica religiosa y las formas situacionales de distribución de ambas lenguas en el marco de un mismo evento de habla - es decir de cada acontecimiento concreto que permite la interacción comunicativa entre sus miembros (GUMPERZ; HYMES, 1972), relacionado en este caso con la expresión de la religiosidad.

Debido a su larga y compleja historia de misionalización, los chanés se reconocen, en un principio, mayormente católicos, aunque la observación etnográfica sugiere que tal vez no haya en ello una adhesión positiva y reflexiva sobre el arraigo cotidiano de ese credo religioso sino más bien una forma de diferenciarse del creciente evangelismo. De hecho, los poblados chanés de la provincia de Salta en los cuales he llevado a cabo este estudio han permanecido desde mediados y hasta finales del siglo XX bajo la órbita de la Orden Franciscana; por ejemplo, en el caso del poblado de Tuyunti, este ha sido incluso fundado como misión en 1946. Si bien los otros tres poblados chanés no se constituyeron como misiones, quedaron bajo la tutela de esta orden religiosa hasta entrada la década de 1990. Debido a esta coyuntura histórica, en todos los poblados existen capillas en las que se celebra la misa con regularidad. Además de ello, durante las últimas tres décadas - y tal como en otros lugares del Chaco - ha habido un avance significativo del evangelismo, por lo que los cuatro poblados cuentan al menos con un culto evangélico perteneciente a distintos movimientos en los que se celebran varios encuentros semanales ${ }^{4}$.

Hoy en día, los católicos practicantes asisten a misa una vez a la semana o cada quince días en las capillas de los poblados, o bien se trasladan a poblados criollos vecinos a tal fin. En el caso de la misa que se celebra en los poblados indígenas, es oficiada por un sacerdote que proviene de fuera del poblado. Algunos grupos cuentan con material bilingüe -especialmente oraciones y cantos traducidos a la lengua indígena - para la misa. En la mayoría de los casos, el trabajo de traducción que ha permitido que se contara con ese material ha sido realizado por los maestros auxiliares bilingües de las escuelas. Sin embargo, éstos no son utilizados de manera regular durante la celebración de la misa, con lo cual la participación en este evento de habla se produce casi en su totalidad en castellano.

Como ya he mencionado, todos los poblados chanés cuentan actualmente con cultos evangelistas pertenecientes a distintos movimientos, principalmente Asamblea de Dios Ministerio Misión Cristiana Iglesia de Cristo Jesús y Movimiento Cristiano y

\footnotetext{
4 Por ejemplo, para el caso mocoví, cf. Altman (2011); para el caso toba, cf. Wright (2003), Ceriani Cernadas (2005) y Ceriani Cernadas y Citro (2005); para el caso wichí, cf. García (2002) y Contini (2015).
} 
Misionero. Estos cultos se han instalado en los poblados chanés principalmente desde fines de la década del 2000 y principios de la década de 2010. Generalmente, en estos espacios religiosos se predica en castellano y los pastores son indígenas oriundos de los mismos poblados. Sólo se predica en lengua indígena si se presenta en la celebración un adulto mayor que no posea una competencia comunicativa sólida en castellano; en este caso, se privilegia que la mayor parte del público sea capaz de comprender lo que se está predicando y por eso se observa un cambio de código de acuerdo con la audiencia presente. Al contrario de lo que sucede en el caso de la misa católica, en los cultos evangelistas se puede observar un cambio de código más fluido. No sólo los pastores que dirigen la celebración optan por un código u otro de acuerdo con su propia competencia comunicativa y la de la audiencia, sino también con la de aquellas personas que participan activamente transmitiendo sus testimonios de conversión y plegarias tanto en castellano como en la lengua indígena. Esto puede deberse al hecho de que la concurrencia es muchas veces interétnica, tanto en el sentido indígena (por ejemplo, tapietes) como no indígena (criollos).

El catolicismo y el evangelismo conviven, a la vez, en condición de sincretismo con las creencias cosmológicas propias de los chanés. Tomemos solamente un caso para ver de qué manera se plasma el bilingüismo en estos casos. Uno de los principios fundamentales para comprender la cosmología chané es opaite iya, "todo tiene dueño" (VILLAR, 2011, p. 158-159), lo cual significa que cada elemento del mundo "natural" se encuentra administrado por entidades personalizadas llamadas iyareta o "dueños" ${ }^{\prime 5}$. La obtención de recursos del monte sigue, por lo tanto, el canal de una relación social hombre-dueño que está regulada por modos de proceder ritualizados y regida por rogativas que son formas discursivas relativamente estandarizadas de negociación. Cada vez que una persona ingresa al monte para cazar, obtener madera o arcilla, debe pedir entonces permiso a los dueños para extraer lo que necesita y agradecerles luego mediante pequeñas fórmulas más o menos estandarizadas: por ejemplo, cheru, iguira iasata arata cherëta ("padre mío, cortaré este árbol para llevarlo a mí casa"). De esta manera, un hombre puede pedir permiso al "dueño del árbol" para talar un árbol llamándolo respetuosamente cheru , "mi padre". Es probable que el dueño del monte se "ofenda" frente a aquella persona que no solicita el permiso correspondiente o que sale del monte sin agradecer por lo que ha tomado. En el caso de no ser tratado con el debido respeto, el "dueño del árbol" puede castigar al intruso extraviándolo en el monte o haciéndole tener pesadillas o sueños perturbadores. Es importante señalar, en este sentido, que tanto las fórmulas para pedir permisos como para agradecer a los dueños suelen pronunciarse generalmente en la lengua indígena, aunque, de acuerdo con varios hablantes, tendrían el mismo efecto si fuesen enunciadas en castellano.

\footnotetext{
Esta cosmología es común a muchos otros pueblos indígenas sudamericanos. Para el caso tapiete, ver Hirsch (2006) y Ciccone (2016); para el caso toba, Messineo (2014); para el caso achuar, Descola (1986); para el caso araweté, Viveiros de Castro (1992); para el caso sharanahua, Déléage (2005).
} 


\section{Los Chanés y sus "Otros"}

La mirada sobre un "otro" que se diferencia de un "nosotros" se encuentra en el corazón de las investigaciones antropológicas. Sin embargo, los significados específicos que dan forma en cada escenario a los contrastes de "identidad" y "alteridad" se encuentran inevitablemente vinculados con las formas concretas que adoptan las relaciones regionales entre los diversos grupos étnicos (LÉVI-STRAUSS, 1991; COMBÈS; SAIGNES, 1995). En el caso chané, la lengua constituye un elemento que no puede dejarse de lado cuando se estudian las relaciones interétnicas. Por ello, a continuación, abordaré algunos detalles acerca de la construcción de las relaciones interétnicas - específicamente plasmadas en el plano de la lengua - que los chanés mantienen con dos grupos humanos principales: por un lado, con los "criollos" o karai con quienes mantienen contacto diario y, por otro lado, con otros grupos étnicos guaraní hablantes de la zona: ava, isoseños, simbas, tapietes. Comparativamente, esta segunda vinculación cobra gran importancia dado que, cuando se habla de "relaciones interétnicas", o de "alteridad" en contextos indígenas generalmente se pone el foco en las relaciones entre los grupos indígenas y las sociedades externas, dejando de lado las relaciones que los primeros mantienen a la vez con los demás grupos indígenas (HIRSCH, 2006; COFFACI DE LIMA; CÓRDOBA, 201 1; CICCONE, 2015).

De hecho, es importante tener en cuenta que en los mismos poblados que se autoadscriben como "chanés" no sólo habitan hablantes de la variante homónima sino también hablantes de otras variantes. Esto se debe a varios hitos estructurantes de la historia regional sobre todo del siglo XIX y XX. Ya hacia mediados del siglo XIX, como consecuencia del establecimiento de ingenios azucareros en el norte argentino, comienzan una serie de movimientos migratorios importantes de indígenas provenientes de Bolivia hacia Argentina - bautizada en guaraní chaqueño como Mbaaporenda "lugar del trabajo"- en busca de nuevos horizontes laborales. Por otro lado, la situación de las misiones indígenas bolivianas que se mantiene estable hasta mediados del siglo XX sufre cambios importantes debido a su secularización, lo cual precipita aún más estos flujos migratorios. Como corolario, esto desplazamientos se intensificaron luego debido a la guerra del Chaco (MÉTRAUX, 1930; NORDENSKIÖLD, 2003 [1922]; BOSSERT; COMBÈS; VILLAR, 2008; LANGER, 2008; CÓRDOBA; BOSSERT, 2015). Por estas razones, no es de extrañar que en varios de los poblados chanés puedan encontrarse hablantes de otras variantes del guaraní chaqueño que se autoperciban como étnicamente diferentes, ya sea ava, isoseños o simbas.

Acerca del primer grupo - los karai -, podemos decir que todos los poblados chanés se encuentran a una distancia relativamente corta de algún poblado criollo y los pobladores se desplazan a ellos casi a diario por distintos motivos como trabajar, realizar compras, recibir atención médica, realizar trámites o asistir a la escuela. A su vez, los habitantes de algunos poblados criollos concurren a los poblados chanés con el fin de llevar a sus niños a la escuela - muchos niños criollos, por una cuestión de cercanía, asisten a las escuelas de los poblados indígenas -, para participar en fiestas tradicionales, como el arete guasu o "carnaval", o bien para realizar transacciones comerciales -por ejemplo, en el caso de los proveedores de mercadería de proveedurías. 
En este escenario de contacto cotidiano, entre los habitantes de los poblados chanés y los de los criollos circulan diferentes representaciones ideológicas sobre el castellano y la lengua indígena que ponen de manifiesto las relaciones de alteridad existentes. Por un lado, se observa que los criollos mantienen una mirada exótica de la lengua indígena: así, muchos padres criollos que envían a sus niños a las escuelas de los poblados chanés por una cuestión de cercanía encuentran "agradable" o "bonito" el hecho de que sus hijos aprendan la lengua indígena, sobre todo porque en la primaria los niños aprender los números, los nombres de animales y algunas canciones en dicha lengua ${ }^{6}$.

Además, para la población criolla, la lengua indígena representa una marca diferenciadora de la condición indígena. En este sentido, la lengua es percibida como un atributo esencial, condición necesaria para que una persona sea considerada indígena, homogeneizándose, de esta manera, la situación lingüístico-antropológica bajo la suposición indiscutida de que todos los indígenas hablan igualmente la lengua.

También es notable, por parte de los criollos, el uso de ciertos vocablos en la lengua indígena para referirse a los chanés. El término kuña, por ejemplo, puede resultar interesante para comprender las relaciones entre los chanés y los criollos. Este término, que significa "mujer", y que no posee ninguna connotación particular en la lengua indígena, es tomado por el criollo para marcar de manera despectiva el origen indígena de una mujer. Kuña adquiere, por lo tanto, una connotación negativa fuera del ámbito del poblado.

Por otro lado, también debemos considerar las ideologías de los chanés acerca de los usos de la lengua indígena y del castellano en situaciones de contacto con la sociedad regional y nacional, sobre todo cuando concurren a un poblado criollo y mantienen un contacto cotidiano con la población karai. El castellano es considerado como un vehículo para obtener movilidad social ascendente, sobre todo en el ámbito de la educación. Además, su aprendizaje es visto como una herramienta esencial de negociación con la sociedad nacional. Más allá del ámbito educativo, el dominio de la lengua de los karai adquiere asimismo una gran importancia, por ejemplo, en la comercialización de "artesanías" como cerámica o máscaras. Aquí el castellano se transforma en una herramienta de negociación para tratar con turistas locales, grandes mayoristas e incluso ONGs dedicadas al "comercio justo", a fin de obtener el mejor precio de venta posible para sus mercancías.

El manejo del castellano también posee una importancia crucial en el acceso a los servicios de salud pública - ya sea en el hospital o en las salas de atención primaria -, en la realización de trámites e incluso en las actividades recreativas, como por ejemplo los carnavales o partidos de fútbol organizados frecuentemente con equipos de Aguaray, Tartagal, o Salvador Mazza. En este contexto, el castellano, al igual que en la adopción de costumbres, comidas, vestimenta y tecnología karai, se concibe como medio para ampliar las redes sociales. Más allá de la utilidad de dominar el karai ñee o "lengua de

\footnotetext{
Compárese esto, por ejemplo, con el caso de la situación bilingüe guaraní-castellano registrada para la provincia argentina de Corrientes. Según describe Cerno (2011), las lenguas escogidas para una conversación y las formas de hablar constituyen diacríticos que están relacionados con "estereotipos culturales" como el "guarango sagua'a" o "ava" que refiere a personas con escasa competencia comunicativa en castellano; el "porteño", "ñembotuchase" o "ikatese" que, por el contrario, no posee una competencia comunicativa en guaraní; y, finalmente, el "guaranisero", es decir, aquel cuya competencia comunicativa sólida en ambas lenguas le permite adaptarse a mayor cantidad de situaciones cotidianas de interacción.
} 
los criollos", existe un interés que parecería más sistemático por expandir el horizonte potencial de las relaciones sociales (COMBÈS; VILLAR, 2007).

En la esfera política, al mismo tiempo, el castellano también se constituye como una herramienta importante a la hora de entablar tratos o negociaciones con el gobierno municipal e instituciones relacionadas con asuntos indígenas. Por ejemplo, es común que los indígenas deban recurrir al gobierno municipal en aquellos casos en los que quieran solicitar fondos para mejoras en materia de infraestructura, ayuda social y documentación. El uso del castellano posibilita llevar a cabo estos reclamos o peticiones. Inclusive, desde la misma institución escolar, los maestros auxiliares bilingües mantienen contacto con el Ministerio de Educación, el cual ofrece, actualmente a través del Consejo Educativo Autónomo de Pueblos Indígenas (CEAPI), cursos de capacitación de los cuales participan maestros auxiliares pertenecientes a diferentes grupos indígenas.

En el caso puntual de la oratoria política, uno de los espacios privilegiados para observarla es en la ya mencionada 'asamblea comunitaria' o yemboati. La asamblea es un espacio público de discusión de gran relevancia al interior de cada comunidad entre los grupos guaraní hablantes (HIRSCH; ALBERICO, 1996; LOWREY, 2007); posee funciones deliberativas y su autoridad puede, en ciertos casos, elevarse por sobre la del 'cacique' o mburuvicha. Aquellas personas que toman la palabra en este tipo de eventos suelen, por lo general, caracterizarse como ñee iya. Los ñee iyareta 'dueños de la palabra' son personas capaces de expresarse con elocuencia en la lengua indígena y en castellano dando discursos en los que exaltan la cultura tradicional y el conocimiento de la historia local. Ahora bien, no sólo la asamblea nos permite observar este género discursivo, sino también otros espacios públicos como los actos políticos o escolares. Estos oradores deben ser capaces de transmitir su mensaje de forma efectiva; esto implica que la oratoria sea lo suficientemente flexible como para responder a un medio o una coyuntura cambiantes. La elección de uno u otro código, en este sentido, parece una elección estratégica de cada hablante según el efecto y contexto que desee crear. Tomaré para ilustrar ello un breve discurso público en guaraní chaqueño emitido por un ñee iya de 41 años de ìkira, actual presidente del Centro Comunitario de aquel lugar, en ocasión de un reconocimiento a las artesanas de distintos poblados chanés de la zona que se realizó en el poblado de Tuyunti en marzo de 2016 por iniciativa de la municipalidad local, y del que participaban familias de distintos poblados y algunas autoridades municipales, además de las artesanas homenajeadas:

Pepuama tëtarareta, ñanderami, ñandeyari, tapiireta, kuñareta. Añae ae día importante kuae kuña comunidadreta, kuñareta oimeta. Ime kuñareta comunidadpe uparaïkireta. Oseta opaite kuape ñande piapi jaereta umbaapo kuarai comunidad pe. Jaereta ampo consejo ime ñandevae. Che ambuadora opaite kuñareta ö̈, mburuvichareta oï a tenondeareta. Opaite kuape representa ñanderëtara. Yasurupai tëtarareta, mburuvichareta.

La traducción sería:

Buenos días a la comunidad, a nuestros abuelos, a nuestras abuelas, hombres y mujeres. Hoy es un día importante para las mujeres, para las mujeres de las comunidades. Las mujeres trabajan en la comunidad. Ellas trabajan de esta forma en la comunidad. Ellas nos dan consejos a todos nosotros. Yo aprecio a 
todas las mujeres, a las autoridades, a los antepasados. Todos ellos representan nuestra comunidad. Gracias al poblado, a las autoridades.

Como podemos observar aquí, el eje central del discurso está en destacar y valorizar, como es típico en estos casos, las tradiciones culturales. Además, es importante destacar el hecho de que el discurso ha sido pronunciado únicamente en la lengua indígena a pesar de que allí se encontraban presentes también algunas pocas personas de origen criollo. El ñee iya opta por un código particular, en este caso la lengua indígena, teniendo en cuenta que la audiencia a la que va destinado el mensaje - artesanas homenajeadas y sus familiares - pertenece mayormente a las familias más "tradicionales".

En lo que se refiere por otro lado a la relación cotidiana con otros grupos guaraní hablantes, los chanés acostumbran a calificar a los hablantes de otros dialectos del guaraní chaqueño o chiriguano como hablantes de una lengua diferente de la suya. Este hecho llama la atención, ya que tanto la estructura gramatical como una buena parte del léxico se revelan iguales, o cuanto menos similares, en las distintas variantes dialectales (DIETRICH, 1986; GUSTAFSON, 2014). Ahora bien, las pequeñas diferencias que existen entre los dialectos de esta lengua desempeñan no obstante un papel fundamental para la identificación étnica de los chanés en relación con otros grupos guaraní hablantes. Uno de los rasgos que más entra en juego en este contexto es la alternancia en algunas diferencias entre los fonemas sibilantes /s/ y /t $\mathrm{f}$. Así, el fonema sibilante fricativo /s/ puede observarse principalmente entre los isoseños de la zona, mientras que el fonema sibilante /t $\mathrm{f} /$ es mucho más observado entre los avas y chanés. Este rasgo fonético actúa como uno de los principales marcadores de la identidad chané y es continuamente destacado por los hablantes: la forma más perceptible del mismo se da en la primera persona del singular che ' $\mathrm{yo}^{\prime}$ ', que es pronunciada /se/ entre los isoseños y $/ \mathrm{t} \mathrm{e}$ / entre los chanés y los avas.

Otra diferencia puede encontrarse en la prosodia. En efecto, muchos chanés describen que el habla de los otros guaraní-hablantes como una lengua de habla "rápida", "ligerita", con "acento" o con "admiración". Incluso, algunos hablantes asimilan la forma de hablar de otras variantes dialectales con la del guaraní paraguayo. Por contraposición, describen al dialecto hablado por ellos como una lengua que se habla más "despacio" o "lento", pero "correctamente" y "derecho", con el fin de lograr una mejor comprensión por parte del receptor.

Otro punto para considerar es el hecho de que, cuando los chanés describen el panorama sociolingüístico de los otros poblados con población de origen guaraní de la zona, son recurrentes las alusiones al corte de la transmisión lingüística. Esto, para ellos, denota una aproximación creciente de los otros grupos guaraníes a la población criolla ligada con el supuesto abandono progresivo del guaraní en favor del castellano. Sin embargo, lo cierto es que, a su vez, este corte en la transmisión intergeneracional de la lengua indígena es un fenómeno también puede observarse entre los mismos chanés (MORANDO, 2015; 2021).

Entonces, a pesar del hecho etic de que los especialistas hayan demostrado la unidad lingüística del guaraní chaqueño o chiriguano -que en principio incluye al chané, al ava, al isoseño y al simba como "dialectos"-, los habitantes de los poblados chanés 
se distinguen "emicamente" a sí mismos por un etnónimo específico que a su vez se corresponde, en su visión, con una lengua distinta. La variante dialectal hablada por los chanés recibe entonces efectivamente una valoración positiva, construyéndose en términos de marca identitaria por contraposición con los demás dialectos hablados por otros grupos de origen guaraní de la zona.

\section{Nuevos Desafíos y Perspectivas del Bilingüismo a Comienzos del Siglo XXI}

Avanzando sobre el tema de este trabajo, quiero reservar este último espacio para tratar brevemente algunos fenómenos recientes que influyen en los usos actuales de la lengua indígena y del castellano entre los chanés, que son testimonio de las diversas formas contemporáneas en las que este grupo se integra a las realidades locales, nacionales y globales. En particular, quiero mencionar el caso de los medios de comunicación y el uso cada vez más extensivo de las nuevas tecnologías de la comunicación que dan origen a nuevos géneros comunicativos, sobre todo a partir del uso de las redes sociales.

La información sobre noticias de la localidad, de la provincia y de otros lugares del país o del mundo llega a los poblados chanés principalmente por medio de la televisión y la radio. Estos medios difunden mayormente información en castellano, a excepción de unas pocas emisiones de alguna estación de radio local o del vecino país de Bolivia en el que se habla el guaraní chaqueño. Sin embargo, el surgimiento de las nuevas tecnologías masivas de información y comunicación ha dado origen a nuevos espacios de interacción. La aparición de estas formas de comunicación genera un nuevo espacio de interacción - el de la pantalla de un ordenador o de un teléfono celular - en el que media el uso de un artefacto tecnológico y que se lleva a cabo mayormente de manera escrita y sincrónica, lo que produce cambios importantes en el plano de las relaciones interpersonales (NOBLIA, 2009). El guaraní chaqueño, al igual que muchas otras lenguas indígenas de Sudamérica, no ha permanecido al margen de estos procesos.

Los modos en los que los chanés se sirven del castellano y del guaraní chaqueño como recursos para la construcción cotidiana de la identidad pueden contribuir a explicar los complejos procesos de cambio de código o, por el contrario, el uso de un solo código, y estas experiencias comunicativas deben ser vistas como resultado de las actividades sociales de las cuales participan habitualmente los chanés, así como también de las lenguas que se ven implicadas en ellas. La relación entre la lengua y los nuevos modos de comunicación es compleja y problemática, porque la naturaleza mediada de estos intercambios plantea la posibilidad de interactuar con un interlocutor que está físicamente ausente, lo cual posibilita a su vez modos particulares de interacción en los que los participantes marcan y negocian sus posiciones y definen interactivamente su identidad.

Tomaré para ejemplificar esto brevemente un fragmento de conversación proveniente de la red social Facebook, puesto que es uno de los espacios más utilizados para la interacción virtual por los chanés. La interacción se encuentra organizada sobre la base de la alternancia de turnos, conformándose de esta manera pares dialógicos y secuencias interaccionales. Esto permite organizar los intercambios entre los interlocutores marcando 
el papel de cada uno de ellos en la interacción. En la conformación de los turnos, sin embargo, pueden advertirse ciertas rupturas y superposiciones propias de la naturaleza del canal que se utiliza para este tipo de interacciones en el que participan diferentes personas casi de manera simultánea. Esto lleva a su vez a realizar una lectura particular de estos textos, que implica identificar de antemano los interlocutores que forman parte del intercambio dialógico, así como la forma en la que se articulan los turnos y las secuencias discursivas:

Cuadro l - Fragmento de conversación bilingüe en la red social Facebook

\begin{tabular}{|c|c|}
\hline Publicación inicial & $\begin{array}{l}\text { lA: Puama opaete peara...!! Muy bs días a to- } \\
\text { dosss..!! }\end{array}$ \\
\hline Comentarios a la publicación inicial & $\begin{array}{l}\text { 2B: Las primerass palabras q kieren decir?? } \\
\text { 3C: Puma } \\
\text { 4B: Creo pensar q esta escrito en idioma cha- } \\
\text { ne? Quechua? Mataco? No lo se pero es lindo } \\
\text { aprender de nuestra cultura } \\
\text { 5A: Es Chane...la lengua materna..el idioma es } \\
\text { part d nuestra identidad...hay q conservarlaa...! } \\
\text { 6B: Si si exactooo q no se pierdan las costum- } \\
\text { bres, costumbre de nuestroo aguarayy saludos } \\
\text { desde bsas } \\
\text { 7A: Lo que está en castellano es traducción de } \\
\text { la primera frase } \\
\text { 8B: Q significan esas palabras } \\
\text { 9D: Me lo enseñas? } \\
\text { 10B: Si x favorr da clases ja } \\
\text { 11E: Erei... } \\
\text { 12E:Bueno...jjjja...igualmente amiga... (-) } \\
\text { 13 F: Caruma... }\end{array}$ \\
\hline
\end{tabular}

Fuente: Morando (2021, p. 281-282)

Aquí pueden observarse claramente algunas fórmulas comunes de salutación que se corresponden con el discurso oral y actúan como disparador de las conversaciones y estructurador de los turnos de habla: [Puama opaete peara] ('Buenos días a todos') (1A), [Caruma] ('Buenas tardes') (13F). También resulta interesante analizar, aunque más no sea brevemente, la forma en la que los distintos recursos verbales son utilizados por los interlocutores a fin de indexar sus posiciones, especialmente con respecto a la pertenencia étnica. En este caso, la utilización inicial de la lengua indígena suscita una serie de respuestas. Mientras que algunos interlocutores ( $\mathrm{C}$ y F) corresponden al saludo publicado en la lengua indígena, otros reaccionan con una cierta sorpresa y curiosidad aventurando en algunos casos de qué lengua se trata e incluso pidiendo a la interlocutora A que dé clases: [Creo pensar q esta escrito en idioma chane? Quechua? Mataco? No lo se pero es lindo aprender de nuestra culturaa], [me lo enseñas?], [si x favorr da clases 
ja]. En respuesta a esto, la interlocutora A responde en qué lengua está escrito el mensaje y deja explícito que la lengua es parte de la identidad y como tal debe ser "conservada".

El estudio del bilingüismo en estos contextos comunicativos puede aportar datos sobre las nuevas formas en las cuales las prácticas comunicativas y las ideologías lingüísticas intervienen en los procesos de posicionamiento individual, social y étnico, lo cual nos ofrece un terreno analítico fecundo para el estudio del uso de ambas lenguas, sus dominios de empleo y asimismo los factores que inciden en la elección de una u otra de acuerdo con el contexto y un conjunto de ideologías que configuran el empleo de determinadas prácticas comunicativas como indicadores de identidad.

\section{Reflexiones Finales}

Este trabajo comenzó señalando que el caso chané resulta particularmente interesante para considerar el problema del bilingüismo y la diglosia debido a que a lo largo de la historia este grupo atravesó un doble proceso de quiebre lingüístico. En términos de Siguán y Mackey (1986), podríamos decir que la situación de bilingüismo actual entre los chanés obedecería a dos factores históricos principales. Por un lado, debido a un proceso de expansión de un pueblo sobre un territorio en el que se hablaban otras lenguas - esto es, el avance tupí-guaraní hacia el piedemonte andino que se produjo a partir del siglo XVI, proceso mediante el cual estas bandas se integraron con población de origen chané-arawak imponiéndose la lengua de los primeros. Pero, a la vez, por otro lado, como consecuencia del avance del frente colonizador principalmente durante el período colonial, se impuso sobre esta población el castellano como instrumento de comunicación formal.

He pretendido aquí describir etnográficamente algunos de los usos e ideologías chanés acerca de la lengua indígena y del castellano, como así también de sus relaciones diversas y contextuales con el posicionamiento social, la definición étnica y las prácticas comunicativas. Habida cuenta de la situación sociolingüística chané en diversos contextos, podríamos describir este caso como un caso de bilingüismo con diglosia ya que nos encontramos en el campo con un panorama que devela que los chanés son, hoy en día, mayormente bilingües en castellano y en guaraní chaqueño y que cada una de estas lenguas es utilizada cotidianamente en distintas situaciones y asociada con determinados contextos sociales (escuela, misa, culto, actividades laborales, entre otros). Debido a las crecientes presiones del frente criollo, lo cierto es que el uso del castellano se consolida cada vez más en ciertos ámbitos específicos en los que su uso resulta ya inevitablemente indispensable; esto resulta claro, por ejemplo, en el caso de lo escolar/académico.

Ahora bien, lo cierto es que, como consecuencia de la coyuntura histórica particular de la región, en los poblados chanés no sólo conviven personas de origen étnico chané sino también de otras parcialidades étnicas - ava, isoseño, simba - que hablan distintas variantes del guaraní chaqueño. A pesar de una ampliamente demostrada "unidad dialectológica" entre las distintas variantes de esta lengua (DIETRICH, 1986; GUSTAFSON, 2014) y, si bien no podemos decir que una de las variantes detente necesariamente una posición de mayor codificación o estandarización, los elementos distintivos que los 
diferencian se traducen ciertamente en determinados posicionamientos identitarios. Esta situación se complejiza aún más si tenemos en cuenta el hecho de que la lengua no es el único factor a partir del cual se construye el reconocimiento identitario frente a estas otras parcialidades étnicas, sino que en ello también intervienen otros factores, principalmente la trayectoria etnohistórica de cada grupo familiar particular. Inclusive, siguiendo el planteo de Gal y Woolard (1995) podríamos decir que en este caso las adscripciones étnicas marcan "categorías culturales de comunicación" ya que estas variantes de la lengua guaraní habladas son conceptuadas no como "variantes" sino como "lenguas", "idiomas" o ñee diferentes.

Lo que se observa, en definitiva, es una comunidad de habla heterogénea y dinámica en la que se vislumbra una coexistencia compleja de prácticas y usos lingüísticos relacionados con un conjunto determinado de factores históricos, sociales, políticos, parentales, religiosos, étnicos y económicos. Podemos decir, entonces, que, como cualquier práctica social, las prácticas comunicativas están estrechamente relacionadas con variables en función de las cuales los miembros de la comunidad de habla construyen ideologías lingüísticas que median entre lo social y las formas de habla. Las actitudes individuales y colectivas hacia el castellano y el guaraní chaqueño constituyen pues un factor importante para comprender la dinámica específica de la situación de contacto intercultural que existe entre los chanés y los mecanismos más generales de la socialización, la organización sociopolítica o los procesos locales de construcción de la identidad étnica.

Si bien algunos contextos nos revelaron un empleo fluido pero de ambas lenguas - por ejemplo, las celebraciones religiosas -, en otros ámbitos logré identificar un cruce más problemático entre bilingüismo y sociabilidad: así, en líneas generales, comprobé que, tanto en la práctica cotidiana como en la ideología, el uso del chané predomina en el seno de las familias más vinculadas con la tradición cacical -por tanto autopercibidas e incluso percibidas usualmente por los demás como "puras"-, así como el castellano prima en la rutina comunicacional cotidiana de aquellas otras familias que poseen un mayor contacto con el universo criollo. En efecto, los matices que revela la práctica bilingüe y los grados de competencia comunicativa que cada hablante posee en la lengua indígena y en castellano permite abrir el juego al estudio antropológico de las nuevas formas en las cuales las prácticas comunicativas y las ideologías lingüísticas intervienen en los procesos de posicionamiento individual, social, político, identitario y/o étnico.

\section{Agradecimientos}

Agradezco al Dr. Diego Villar por los comentarios a las versiones preliminares de este trabajo, así como a los evaluadores anónimos y al equipo editorial de la revista por la revisión exhaustiva de las informaciones presentadas. Reconozco también a todos aquellos que me acogieron desinteresadamente y me brindaron su apoyo en las comunidades chanés de la provincia de Salta en las que he realizado trabajo de campo desde el año 2012. La investigación de la cual han sido producto estos datos fue financiada por medio de una beca doctoral y postdoctoral del Consejo Nacional de Investigaciones Científicas y Técnicas (CONICET) de Argentina. 


\section{Referencias}

ADMIRAAL, Femmy. Taal en Socialisatie Spaans en Guaraní in Isoso, Bolivia. 2006. $96 f$. Tesis (Doctorado) - Universiteit van Amsterdam, Amsterdam, 2006.

AIKHENVALD, Alexandra. The Arawak language family. In: DIXON, Robert; AIKHENVALD Alexandra (ed.). The Amazonian languages. Cambridge: Cambridge University Press, 1999. p. 65-106.

ALTMAN, Agustina. Historia y conversión: el evangelio entre los mocoví del Chaco Austral. Runa, Buenos Aires: FFyL-UBA, v. 32, n. 2, p. 127-143, 2011.

BORTON, Laureano et al. Una aproximación a las ideas y supuestos sobre el sujeto de aprendizaje en situaciones de interculturalidad. In: HIRSCH, Silvia; SERRUDO, Adriana (Comp.). La Educación Intercultural Bilingüe en Argentina: identidades, lenguas y protagonistas. Buenos Aires: Noveduc Libros, 2010. p. 197-222.

BOSSERT, Federico. Los chané a través del Gran Chaco. Suplemento Antropológico, Asunción: CEADUC, v. 43, n.1, p. 283-338, 2008.

BOSSERT, Federico; COMBÈS, Isabelle; VILLAR Diego. La guerra del Chaco entre los chané e isoseños del Chaco occidental. In: RICHARD, Nicolas (ed.). Mala guerra. Los indígenas en la guerra del Chaco (1932-1935). Asunción: Museo del Barro, 2008. p. 203-233.

BRIGGS, Charles. Learning how to ask: A sociolinguistic appraisal of the role of the interview in social science research. Studies in the Social and Cultural Foundations of Language. Cambridge: Cambridge University Press, 1986.

CERIANI CERNADAS, César. Conflicto sociorreligioso y representaciones simbólicas entre Tobas Mormones y Evangélicos. Avá, Posadas: UNAM, v. 7, p. 45-69, 2005.

CERIANI CERNADAS, Cesar; Silvia CITRO. El movimiento del evangelio entre los tobas del Chaco argentino. Una revisión histórica y etnográfica. In: GUERRERO JIMÉNEZ, Bernardo (ed.). De indio a hermano. Pentecostalismo indígena en América Latina. Iquique: Ediciones Campvs, 2005. p. 111-170.

CERNO, Leonardo. Géneros de tradición oral en comunidades rurales de Corrientes. Etnografía, clasificación, documentación. Suplemento Antropológico, Asunción: CEADUC, v. 46, n. 1, p. 203-300, 2011 .

CHOMSKY, Noam. Aspects of the Theory of Syntax. Massachusetts: MIT Press, 1965.

CICCONE, Florencia. Multilingüismo, prácticas lingüísticas y situación de la lengua tapiete en el Gran Chaco argentino y boliviano. In: MESSINEO, Cristina; HECHT, Ana Carolina (ed.). Lenguas indígenas y lenguas minorizadas: estudios sobre la diversidad ( socio) lingüística en la Argentina y países limítrofes. Buenos Aires: EUDEBA, 2015. p. 108-125.

CICCONE, Florencia. Géneros discursivos persistentes y emergentes en tapiete (tupí guaraní): formas de habla y cambio lingüístico en una lengua minoritaria. REA, Salamanca, Universidad de Salamanca, v. 32, p. 171-188, 2016.

CICCONE, Florencia; HIRSCH, Silvia. La incidencia de los materiales didácticos en los procesos de recuperación de la lengua: una experiencia en la comunidad tapiete de Salta. In: TISSERA DE MOLINA, Alicia; ZIGARÁN, Julia (ed.). Lenguas: Investigaciones y experiencias. Salta: Universidad Nacional de Salta - CEPIHA, 2010. p. 239-249

COFFACI DE LIMA, Edilene; CÓRDOBA, Lorena (ed.). Os outros dos outros: relações de alteridade na etnologia sul-americana. Curitiba: EDUFPR, 2011.

COMBÈS, Isabelle. Etno-historias del Isoso: Chané y chiriguanos en el Chaco boliviano (siglos XVI-XX). La Paz: IFEA, 2005.

COMBÈS, Isabelle. De Sanandita al Itiyuro: los chanés, los chiriguanos (¿y los tapietes?) al sur del Pilcomayo. Indiana, Berlín, IAI, v. 24, p. 259-289, 2007. 
COMBÈS, Isabelle; SAIGNES, Thierry. Chiri-guana: nacimiento de una identidad mestiza. In: RIESTER, Jürgen (ed.). Chiriguano. Santa Cruz de la Sierra: APCOB. 1995. p. 25-221.

COMBÈS, Isabelle; VILLAR, Diego. Aristocracias chané. "Casas" en el Chaco argentino y boliviano. Journal de la Société des Américanistes, París, Société des américanistes, v. 90, n. 2, p. 63-102, 2004.

COMBÈS, Isabelle; VILLAR, Diego. Os mestiços mais puros. Representações chiriguano e chané da mestiçagem. Mana, Rio de Janeiro, PPGAS-UFRJ, v. 13, n. 1, p. 41-62, 2007.

CONTINI, Lavinia. El "culto-fiesta" entre los wichí del chaco argentino. Mundo de Antes, Tucumán, UNT, v. 9, p. 227-251, 2015.

CÓRDOBA, Lorena y Federico BOSSERT. El trabajo indígena en economías de enclave. Una visión comparativa (barracas caucheras e ingenios azucareros, siglos XIX y XX). In: CÓRDOBA, Lorena; BOSSERT, Federico; RICHARD, Nicolas (ed.). Capitalismo en las selvas. Enclaves industriales en el Chaco y la Amazonía indígenas (1850-1950). San Pedro de Atacama: Ediciones del Desierto, 2015. p. 111-128.

DÉLÉAGE, Pierre. Le chamanisme sharanahua: enquête sur l'apprentissage et l'épistémologie d'un rituel. 2005. 720f. Tesis (Doctorado) - Ecole des Hautes Etudes en Sciences Sociales (EHESS), París, 2005.

DESCOLA, Philippe. La nature domestique: symbolisme et praxis dans l'écologie des Achuar. París: Editions de la Maison des Sciences de l'Homme, 1986.

DIETRICH, Wolf. El idioma chiriguano: Gramática, textos, vocabulario. Madrid: Cultura Hispánica, 1986.

DOMÍNGUEZ, María Eugenia. Sons, Ritual e História Indígena no Oeste do Chaco. Ilha Revista de Antropología, Florianópolis, UFSC, v. 20, n.1, p. 45-66, 2018.

DORIAN, Nancy. The problem of the semi-speaker in language death. International Journal of the Sociology of Language, Boston, De Gruyter, v. 12, p. 23- 32, 1977.

DREIDEMIE, Patricia. Estrategias discursivas de persistencia cultural: (dis)continuidad del quechua en el "habla mezclada" de migrantes bolivianos en Buenos Aires. 2006. 320f. Tesis (Maestría) - Universidad de Buenos Aires, Buenos Aires, 2006.

FERGUSON, Charles. Diglossia. Word, Nueva York, ILA, v. 15, p. 325-340, 1959.

FISHMAN, Joshua. Who speaks what language to whom and when. La Linguistique, París, PUF, v. 2, p. 67-88, 1965.

GAL, Susan; WOOLARD, Kathryn. Constructing languages and publics: Authority and representation. Pragmatics, Filadelfia, IPrA, v. 5, n. 2, p. 129-138, 1995.

GARCÍA, Miguel. El evangelismo wichí de uno y otro lado del límite étnico. Ciencias Sociales y Religión, Campinas, Unicamp, v. 4, n. 4, p. 105-123, 2002.

GUMPERZ, John; HYMES, Dell. Directions in Sociolinguistics: The Ethnography of Communication. Nueva York: Basil Blackwell, 1972.

GUSTAFSON, Bret. Guaraní. In: CREVELS, Mily; MUYSKEN, Pieter (ed.). Lenguas de Bolivia. La Paz: Plural Editores, 2014. Tomo 3. Oriente. p. 307-368.

HECHT, Ana Carolina. De la familia wichí a la escuela intercultural bilingüe: procesos de apropiación, resistencia y negociación (Formosa, Argentina). Cuadernos Interculturales, Valparaíso, UV, v. 4, n. 6, p. 93-113, 2006.

HECHT, Ana Carolina. Todavía no se hallaron hablar en idioma: procesos de socialización lingüística de los niños en el barrio toba de Derqui (Argentina). Munich: Lincom Europa, 2010. 
HIRSCH, Silvia. The emergence of political organizations among the Guaraní Indians of Bolivia and Argentina: a comparative perspective. In: LANGER, Erik; MUÑOZ, Elena (ed.). Contemporary Indigenous Movements in Latin America. Washington: Scholarly Resources Inc, 2003. p. 81-101.

HIRSCH, Silvia. El pueblo tapiete de Argentina: historia y cultura. Buenos Aires: Universidad de Buenos Aires, 2006.

HIRSCH, Silvia; ALBERICO, Angélica. El don de la palabra: un acercamiento al arte verbal de los guaraní de Bolivia y Argentina. Anthropos, Sankt Augustin, Anthropos Institut, v. 91, n. 1-3, 125-137, 1996.

HIRSCH, Silvia; SERRUDO, Adriana. La educación en comunidades indígenas de la Argentina: de la integración a la Educación Intercultural Bilingüe. In: HIRSCH, Silvia; SERRUDO, Adriana (Comp.). La Educación Intercultural Bilingüe en Argentina: identidades, lenguas y protagonistas. Buenos Aires: Noveduc Libros, 2010. p. 17-44.

HYMES, Dell. Competence and performance in linguistic theory. In: HUXLEY, Renira; INGRAM, Elisabeth (ed.). Acquisition of languages: models and methods. Nueva York: Academic Press, 1971. p. 3-23.

INDEC. Encuesta Complementaria de Pueblos Indígenas (ECPI) - Complementaria del Censo Nacional de Población, Hogares y Viviendas 2001. Buenos Aires: Instituto Nacional de Estadística y Censos de la República Argentina, 2004-2005.

LANGER, Erick. Misiones franciscanas y trabajadores chiriguanos: colonización, aculturación y mano de obra indígena en el sudeste de Bolivia. In: RIESTER, Jürgen (ed.). Chiriguano: Pueblos indígenas de las tierras bajas de Bolivia. APCOB: Santa Cruz de la Sierra, 1995. p. 255-287.

LANGER, Erick. La experiencia chiriguana en la guerra del Chaco y la destrucción de las misiones franciscanas. In: RICHARD, Nicolas (ed.). Mala guerra: los indígenas en la guerra del Chaco (1932-1935). Asunción: Museo del Barro, 2008. p. 235-250.

LÉVI-STRAUSS, Claude. Histoire de Lynx. París: Plon. 1991.

LOWREY, Kathleen. Witchcraft as a metaculture in the Bolivian Chaco. Journal de la Société des Américanistes, [s.l.], v. 93, n. 2, p. 121-152, 2007.

MAGRASSI, Guillermo. El complejo chiriguano-chané. In: INSTITUTO NACIONAL DE ESTADÍSTICA Y CENSOS. Censo Indígena Nacional (Provincias de Chaco, Formosa, Jujuy, Misiones, Salta y Santa Fe). Buenos Aires: Ministerio del Interior, 1968. v. 2. p. 23-60.

MESSINEO, Cristina. Arte verbal qom: consejos, rogativas y relatos de El Espinillo (Chaco). Buenos Aires: Rumbo Sur, 2014.

MÉTRAUX, Alfred. La sécularisation des Missions Franciscaines du Chaco Bolivien. Journal de la Société des Américanistes, París, Société des Américanistes, v. 21, n. 2, p. 420-422, 1930.

MÉTRAUX, Alfred. Tribes of the Eastern Slopes of the Bolivian Andes. Chiriguano and Chané. In: STEWARD, Julian (ed.). Handbook of South American Indians. Washington: Smithsonian Institution, 1948. v. 3. p. 465-485.

MORANDO, María Agustina. Bilingüismo y organización social en la comunidad chané de Tuyunti (departamento General San Martín, provincia de Salta). Suplemento Antropológico, Asunción, Centro de Estudios Antropológicos de la Universidad Católica de Asunción (CEADUC), v. 50, n. 2, p. 257-335, 2015.

MORANDO, María Agustina. Ñande ñee jekove. Lengua y praxis social entre los chanés del Noroeste Argentino. Cochabamba: Itinerarios, 2021. 
MORENO FERNÁNDEZ, Francisco. Principios de sociolingüística y sociología del lenguaje. Barcelona: Ariel, 2012 [1998].

NOBLIA, María Valentina. Modalidad, evaluación e identidad en el chat. Discurso \& Sociedad, UC, v. 3, n. 4, p. 738-768, 2009.

NORDENSKIÖLD, Erland. La vida de los indios. El Gran Chaco (Sudamérica). La Paz: APCOB/Plural, 2002 [1912].

NORDENSKIÖLD, Erland. Indios y blancos en el Nordeste de Bolivia. La Paz: APCOB/ Plural, 2003 [1922].

PALAVECINO, Enrique. Algunas informaciones de introducción a un estudio sobre los chané. Revista del Museo de La Plata, La Plata, UNLP, v. 4, p. 117-131, 1949.

PETZ, Ivanna. Pueblos Originarios, Estados Provinciales y Educación. Un análisis comparativo en Salta y Formosa. La Educación Intercultural Bilingüe en Argentina. identidades, lenguas y protagonistas. In: HIRSCH, Silvia; SERRUDO, Adriana (Comp.). La Educación Intercultural Bilingüe en Argentina: identidades, lenguas y protagonistas. Buenos Aires: Noveduc Libros, 2010. p. 45-70.

ROCCA, Manuel. Los chiriguano-chané. América Indígena, México, UNAM, v. 33, n. 3, p. 743-756, 1973.

SAIGNES, Thierry. Historia del pueblo chiriguano (compilación, introducción y notas: Isabelle Combès). La Paz: IFEA/Plural, 2007.

SIGUÁN, Miguel; MACKEY, William Francis. Educación y bilingüismo. Madrid: Santillana, 1986.

SILVERSTEIN, Michael. Language structure and language ideology. In: CLYNE, Paul; HANKS William; HOFBAUER, Carol. The elements: a parasession on linguistic units and levels. Chicago: Chicago Linguistic Society-University of Chicago, 1979. p. 193-247.

SUSNIK, Branislava. Chiriguanos I: Dimensiones etnosociales. Asunción: Museo Andrés Barbero, 1968.

THOMASON, Sarah. Language contact: an introduction. Washington: Georgetown University, 2001.

VILLAR, Diego. Repensando el complejo cultural chiriguano-chané. In: COMBÈS, Isabelle (ed.). Definiciones étnicas, organización social y estrategias políticas en el Chaco y la Chiquitanía. Lima: IFEA/SNV/El País, 2006. p. 205-244.

VILLAR; Diego. La religión del monte entre los chané. Suplemento Antropológico, Asunción, CEADUC, v. 46, n. 1, p. 151-201, 2011.

VILLAR, Diego; Federico BOSSERT. Máscaras y muertos entre los chané. Separata, Rosario, UNR, v. 14, n. 9, p. 12-33, 2014.

VIVEIROS DE CASTRO, Eduardo. From the enemy's point of view: humanity and divinity in an amazonian society. Chicago: University of Chicago Press, 1992.

WALLIS, Cristóbal Discurso y realidad de la educación intercultural bilingüe en comunidades wichí del Pilcomayo, Salta. ¿Es factible la interculturalidad en la escuela pública? In: HIRSCH, Silvia; SERRUDO, Adriana (Comp.). La Educación Intercultural Bilingüe en Argentina: identidades, lenguas y protagonistas. Buenos Aires: Noveduc Libros, 2010. p. 149-173.

WRIGHT, Pablo. 'Ser católico y Ser evangelio'. Tiempo, historia y existencia en la religión toba. Anthropológicas, Recife, PPGA-UFPE, v. 132, p. 61-81, 2003.

ZIMMERMANN, Klaus. El problema del purismo en la modernización de las lenguas amerindias. In: TERBORG, Roland; GARCÍA LANDA, Laura (Comp.). Los retos de la planificación del lenguaje en el siglo XXI. México: Universidad Nacional de México, 2006. p. 501-524. 


\section{María Agustina Morando}

Profesora de Enseñanza Media y Superior en Ciencias Antropológicas, Licenciada en Ciencias Antropológicas y Doctora en Antropología por la Universidad de Buenos Aires, Argentina. Actualmente se desempeña como becaria postdoctoral del Consejo Nacional de Investigaciones Científicas y Técnicas en el Instituto de Investigaciones de la Facultad de Ciencias Sociales de la Universidad Católica Argentina (IICS/CONICET-UCA). Es miembro del Centro de Investigaciones Históricas y Antropológicas (Bolivia), de la Asociación Paraguaya de Antropología (Paraguay), de la International Society for Folk Narrative Research (Estonia) y de la Société des Américanistes (Francia). Trabaja sobre temas vinculados a la etnografía, la etnohistoria y la lengua de los chanés del Noroeste Argentino (departamento San Martín, provincia de Salta) donde llevó a cabo sus principales campañas de campo.

Endereço profissional: Instituto de Investigaciones de la Facultad de Ciencias Sociales (IICS/UCACONICET), Av. Alicia Moreau de Justo 1600 (C1107AFF, C1107 AFF), Ciudad Autónoma de Buenos Aires.

E-mail: agustinamorando@uca.edu.ar

ORCID: https://orcid.org/0000-0002-2867-3173

\section{Como referenciar este artigo:}

MORANDO, María Agustina. Diglosia y Bilingüismo entre los Chanés: una Reflexión Crítica. Ilha - Revista de Antropologia, Florianópolis, v. 24, n. 1, e791 16, p. 208-232, janeiro de 2022. 